\title{
No change in my asthma!
}

\section{Robert Crouch RN, PhD, FRCN, FFEN (Consultant Nurse/Senior Lecturer) *, Diana Hulbert BSC (Hons) MB BS FRCS FFAEM (Consultant in Emergency Medicine)}

Emergency Department, Southampton University Hospitals NHS Trust, Tremona Road, Southampton SO16 6YD, United Kingdom

\section{History}

A 57 asthmatic male attended the Emergency Department with a query inhalation/ingestion of a foreign body. When taking his prophylactic inhaler, the gentleman felt something hit the back of his throat; the foreign body appeared to have been lodged in the mouthpiece of his inhaler. He described a feeling similar to the opening and closing of a flutter vale (he had an engineering background) in his chest. He self presented to his Occupational Health department was found not to be in respiratory distress but understandably anxious. He was referred to the Emergency Department for investigation.

\section{Examination}

No signs of respiratory distress (trachea central), respiratory rate $17, \mathrm{SpO}_{2} 96 \%$ on air. Uniform chest expansion but decreased air entry noted on the right side on auscultation, percussion resonant

\footnotetext{
Corresponding author. Tel.: +44 2380798839 .

E-mail address: Robert.Crouch@suht.swest.nhs.uk (R. Crouch).
}

both sides. Deep inspiration caused the patient to want to cough.

\section{Findings}

The chest radiograph revealed a coin shaped object in the right main bronchus (see Fig. 1).

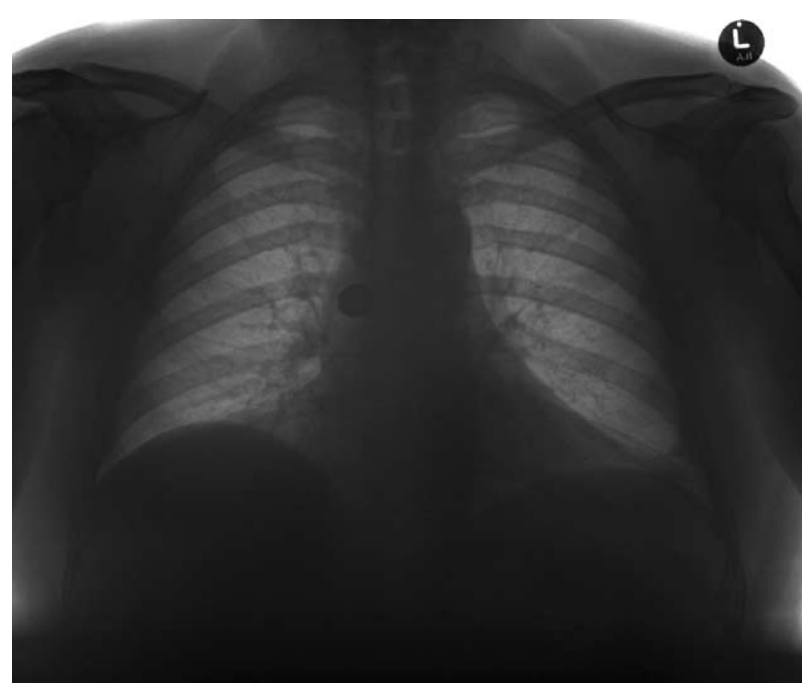

Figure 1 Anterior-posterior chest radiograph. 
The patient was referred to the Cardio thoracic team for a rigid and flexible bronchoscopy, a $5 p$ coin was successfully removed from the right main bronchus and the patient discharged the following day.

\section{Clinical lesson}

Patients should be encouraged to replace the caps on inhalers when not in use and check that the opening of the device is free from foreign bodies.

\section{Conclusion}

This gentleman had a good inhaler technique, but in this case the economic value of prophylaxis in preventing admission is questionable!

N.B. The patient has given written consent for submission of this case study.

Available online at www.sciencedirect.com

science@direct 